Article

\title{
Technical Performance of an Inflatable Solar Dryer for Drying Amaranth Leaves in Kenya
}

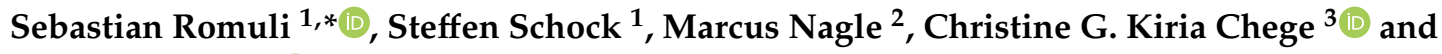 \\ Joachim Müller ${ }^{1}$ (iD \\ 1 Institute of Agricultural Engineering, Tropics and Subtropics Group, University of Hohenheim, \\ 70599 Stuttgart, Germany \\ 2 Agricultural Research and Development Program, Central State University, Wilberforce, OH 45384, USA \\ 3 Regional Office for Africa, International Center for Tropical Agriculture (CIAT), \\ P.O. Box 823-00621 Nairobi, Kenya \\ * Correspondence: info440e@uni-hohenheim.de; Tel.: +49-711-459-23114
}

Received: 16 July 2019; Accepted: 16 August 2019; Published: 20 August 2019

\begin{abstract}
The technical performance of an inflatable solar dryer (ISD) to dry amaranth leaves (Amaranthus spp.) was investigated. To handle the drying of lightweight materials, modification was made by adding an air deflector and trays inside the ISD. Computational performance of the ISD solar energy system was evaluated using MATLAB Simulink. The estimated air mass flow in the inlet of the ISD was $0.75 \mathrm{~kg} / \mathrm{s}$. Using computational fluid dynamics (CFD), the uniformity of air distribution in the ISD was evaluated. The solar radiation reported during good drying performance ranged between 510 and $950 \mathrm{~W} / \mathrm{m}^{2}$. In a controlled charging system, a $100 \mathrm{~W}_{\mathrm{p}} \mathrm{PV}$ module typically generated voltage between 10.22 and $18.75 \mathrm{~V}$. Drying conditions at temperatures of $40^{\circ} \mathrm{C}$ or above were typically achieved in the ISD from 12:00 to 16:00. Temperature inside the ISD could reach up to $69.4^{\circ} \mathrm{C}$ during the day and $13.4{ }^{\circ} \mathrm{C}$ during the night. The highest relative humidity of $97.4 \%$ was recorded during the night. Opening the ISD while mixing the product could lead to considerable heat loss. Fluctuation of solar radiation and shaded areas in the ISD appeared to be the major factors affecting the drying performance.
\end{abstract}

Keywords: off-grid; photovoltaic; postharvest; renewable energy; Simulink; solar bubble dryer

\section{Introduction}

In most developing countries, the long drying times for agricultural commodities have been a major issue, especially for small- and medium-scale food processors [1]. Drying is an energy-intensive process, and solar drying is therefore a preferred method in developing countries with limited resources [2-4]. Cabinet dryers are well known to dry small quantities of vegetables, including amaranth leaves $[2,5]$. The use of a solar dryer has been found to accelerate drying by $30 \%$ to $40 \%$ compared to conventional sun drying depending on the crop [6,7]. In convection dryers, airflow distribution is one of the crucial factors due to its strong impact on the drying temperature [8-10]. An energy-efficient dryer that produces a high-quality product is still not easily accessible among farmers and processors in most developing countries [3]. Recent studies have focused on the development of solar collector and concentrators in a solar dryer $[7,9,11]$. Therefore, a solar tunnel dryer was developed and continuously improved at the University of Hohenheim [6,12]. In this study, the latest version, which is an inflatable solar dryer (ISD), was used. The performance of the ISD has been investigated in a previous work for drying of paddy rice in the Philippines [13]. Due to the positive results, the ISD should now also be applied for high-value crops, such as amaranth leaves (Amaranthus spp.) Amaranth leaves are considered as one of the most nutritive leafy vegetables in Kenya, and the crop is commonly cultivated 
in an intercropping system [14]. The crop grows under semiarid conditions, and high temperatures are necessary to ensure a normal growth of the crop [15]. In Kenya, it has been recognized as a drought-tolerant crop with high nutritional values, which can grow rapidly in tropical areas [16]. As a pretreatment to dry leafy vegetables, blanching is commonly conducted to preserve the texture and color and to inactivate particular enzymes [17], such as peroxidase [18,19].

The objective of this research was to investigate the performance of the ISD for drying amaranth leaves in comparison to conventional sun drying.

\section{Materials and Methods}

\subsection{Inflatable Solar Dryer (ISD)}

A commercialized version of the ISD (SBD 50, GrainPro Inc., Zambales, Philippines) was modified to make it suitable for drying vegetables. The dryer was $26 \mathrm{~m}$ long and $2 \mathrm{~m}$ wide and consisted of a $150 \mu \mathrm{m}$ thick UV-stabilized transparent polyethylene (PE) foil as top layer and a $520 \mu \mathrm{m}$ thick reinforced black polyvinyl chloride (PVC) foil as bottom layer. Both layers were connected by a zipper, forming a foil tunnel that could be opened for loading and unloading the drying area. An air deflector was placed inside the ISD to prevent blowing away the vegetable leaves from the trays. The deflector was made of a plywood board reinforced with a wood beam and held by a metal rod. The tilt angle was $60^{\circ}$ from the ground. The deflector was located in the preheating area, $2665 \mathrm{~mm}$ from the fans and $1000 \mathrm{~mm}$ from the first tray. In order to prevent cuts in the film from sharp edges of the deflector, a $45^{\circ}$ chamfer was made on the upper edges of the sheet (see Figure 1).
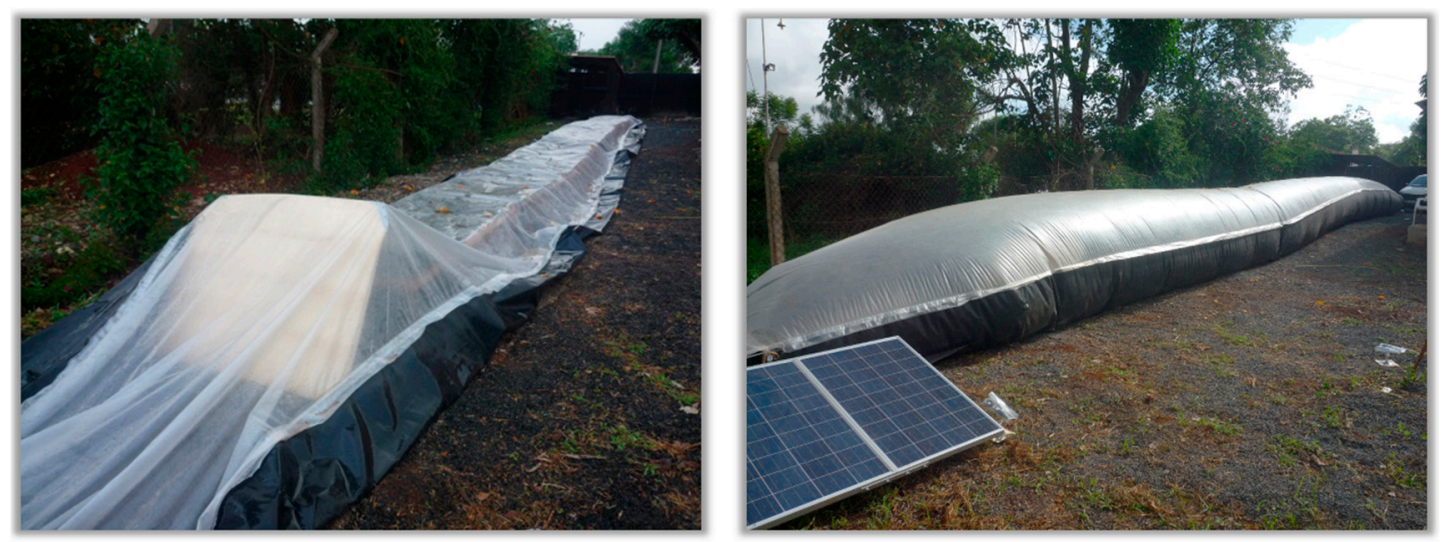

Figure 1. Inflatable solar dryer (ISD) before being inflated (left, note the deflector board) and the inflated ISD during drying experiments (right).

Air was blown through the foil tunnel by two 12 V/2.60 A DC axial fans (RDF2589B12N18S, Runda Electronics CO., LTD, Shenzhen, China), which inflated the tunnel and provided an airflow for drying. The fans were connected to a sealed rechargeable 12 V/75 Ah battery (GT 12-75C, GasTon Battery, Kowloon, Hong Kong), which was continuously charged by two $100 \mathrm{~W}_{\mathrm{p}}$ photovoltaic (PV) modules (Model 100W, Guangxi Sacred New Energy Co. LTD, Shenzhen, China). Each module was $134 \mathrm{~cm}$ long and $110 \mathrm{~cm}$ wide, installed with a tilt angle of $15^{\circ}$ from the ground, and was facing south. During the night, the fan PV modules and battery were brought into a nearby building for safety reasons.

In order to place the drying product, 21 trays covered with $4 \times 4 \mathrm{~mm}$ wire mesh, each with $1065 \times 860 \mathrm{~mm}$ surface area were lined up inside the dryer. Three trays each were placed on a wooden stand, which was $2630 \mathrm{~mm}$ long and $1065 \mathrm{~mm}$ wide. In total, seven wooden stands were placed in the ISD. See Figure 2. 

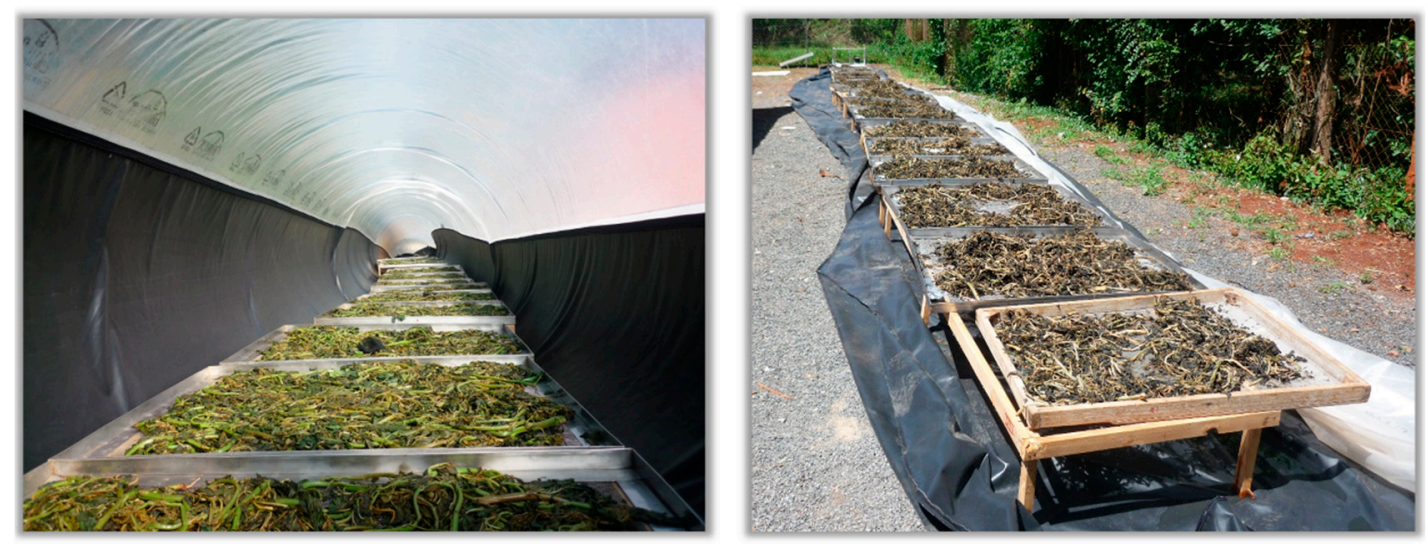

Figure 2. Placement of trays on wooden frames inside the ISD.

\subsection{Simulation of the Photovoltaic Energy Supply System}

The solar energy supply system and the estimated fan performance of the two fans of the ISD were simulated using simulation und model-based design software (MATLAB Simulink, The Mathworks Inc., Natick, MA, USA) using weather data of Nairobi, Kenya. For this purpose, the weather data set KEN_Nairobi-Kenyatta.637400_SWERA was obtained (Meteonorm, Meteotest AG, Bern, Switzerland). The simulation model of the solar battery and the charge controller was set according to Sukamongkol et al. [20]. Based on the climate data input, the voltage of the PV modules, state-of-charge (SOC) of the battery, and fan performance were simulated [21].

The voltage-dependent characteristics per single fan were measured in preparatory tests in a range between 5.4 and $14.8 \mathrm{~V}$, and linear functions were established:

$$
\begin{gathered}
I=0.20 \cdot U-0.43, \quad R^{2}=0.997 \\
n=138.94 \cdot U+176.44, \quad R^{2}=0.995 \\
m=0.028 \cdot U+0.015, \quad R^{2}=0.987
\end{gathered}
$$

with voltage $U(\mathrm{~V})$, current $I(\mathrm{~A})$, rotational speed $n(\mathrm{rpm})$, and air mass flow $m(\mathrm{~kg} / \mathrm{s})$ at a temperature of $25^{\circ} \mathrm{C}$.

The operating mode was assumed to be as follows: initial SOC of the battery is $90 \%$, the system shut downs when SOC falls below $40 \%$, and the system restarts when SOC again exceeds $45 \%$.

\subsection{Computational Evaluation of Airflow inside the ISD}

The air velocity and the airflow distribution above the trays in the ISD could not be measured during the drying experiments. Frequent opening of the ISD for repeated measurements would greatly affect the drying performance [22]. Therefore, a numerical analysis using computational fluid dynamics (CFD) was applied to estimate and visualize the spatial air velocity distribution in the ISD, as suggested by Khazimov et al. [8]. CFD simulation and 3D design of ISD were performed by software Solidworks (Solidworks 2017, Dassault Systèmes, Velizy Villacoublay, France). The air flow was governed according to Navier-Stokes equations, with regard to mass, momentum, and energy conservation laws [23]. Geometry of the ISD, along with the air deflector, the trays, and the stands, was made according to the shape and size of the dryer during drying experiments. Three-dimensional body of the ISD was assumed to be an adiabatic wall. Cavities without flow conditions were excluded. Fluid volume inside ISD was $22.1 \mathrm{~m}^{3}$. Automatic mesh generation was carried out, and total number of the cells was 67,671 . As for the boundary conditions, environmental pressure of $101.3 \mathrm{kPa}$ in the outlet and air mass flow of $0.75 \mathrm{~kg} / \mathrm{s}$ in the inlet were set. The flow was assumed to be fully developed at steady-state condition, and the calculation of the flow was time-independent. The calculation 
converged after 343 iterations. Air temperature at the inlet was considered to be similar to the average ambient temperature, which was set to $30^{\circ} \mathrm{C}$ during the day. Because heat transfer and temperature distribution was excluded in the simulation, temperature rise along the ISD tunnel was neglected. The wire mesh bottom of the trays and the layer of drying material resting on it was assumed as a porous medium with a porosity of 0.6 [24]. The resulting resolution was set at level 8 , which is the highest level.

\subsection{Drying Experiments}

The drying experiments were conducted in Thika, Kiambu County, Kenya (1.042957 $\mathrm{S}$, $\left.37.096790^{\circ} \mathrm{E}\right)$, during December 2016. About $200 \mathrm{~kg}$ of fresh amaranth leaves of the variety "Big Leaf Mchicha" was obtained from the Marikiti market in Nairobi. The leaves were washed in clean water, blanched in water at $90^{\circ} \mathrm{C}$ for about two minutes, and then cooled on an open stand for about five minutes. Subsequently, the leaves were layered $50 \mathrm{~mm}$ thick on the trays using a measuring stick. The weight of the fresh leaves was $8.5 \mathrm{~kg}$ per tray, corresponding with a loading density of $9.3 \mathrm{~kg} / \mathrm{m}^{2}$. As a control for solar drying, a tray loaded in the same way was placed outside the dryer $900 \mathrm{~mm}$ from ground for conventional sun drying. A mesh bag filled with a bunch of leaves was placed on tray 5 in the ISD and another one on the control tray under sun drying. The air velocity at the ISD outlet was regularly measured in the morning and at noon using a digital anemometer (Testo 435, Testo SE \& Co. KGaA, Lenzkirch, Germany).

Drying was started at noon. From the second day on, the fans were turned on at 08:00 and switched off at 18:00. During the drying, mixing was conducted manually every $2 \mathrm{~h}$. To establish drying curves, the mesh bags were weighed at the time of mixing using a digital mass scale (RM/299, Ramtons, Nairobi, Kenya), and about $100 \mathrm{~g}$ of leaves were taken from tray 5 in the ISD and from the control tray under sun drying. The samples were kept in airtight aluminum bags for subsequent moisture content analysis according to DIN CEN/TS 14774-3 [25] at the International Center for Tropical Agriculture (CIAT) laboratory.

Solar radiation $\left(\mathrm{W} / \mathrm{m}^{2}\right)$ and voltage $(\mathrm{V})$ of the $\mathrm{PV}$ modules, along with temperature $\left({ }^{\circ} \mathrm{C}\right)$ and relative humidity (\%) of ambient air and air inside the dyer (tray 5), were measured using USB data loggers (DL-131, DL-191V, DL-181THP, Voltcraft, Hirschau, Germany). Solar radiation and voltage were measured in $1 \mathrm{~min}$ intervals, whereas temperature and relative humidity were measured in $3 \mathrm{~min}$ intervals. Measurements were carried out based on East Africa Time (UTC + 03:00).

\subsection{Statistical Analysis}

Data analysis and graphing software (OriginPro 9.0, OriginLab Corp, Northampton, MA, USA) was used to fit mathematical models.

\section{Results and Discussion}

\subsection{Estimated Performance of the ISD Solar System}

Figure 3 presents solar radiation of Nairobi on 8-11 December 2016, together with the estimated course of SOC and voltage of the battery and resulting air mass flow of the two fans of the ISD. The fans were assumed to be switched off daily from 18:00 to 08:00, which was indicated by constant SOC and zero voltage in the simulation. When the solar system was switched off, the lowest battery SOC was noted as $76.3 \%$. During operation, battery voltage and air mass flow of the fans varied from 12.3 to $13.1 \mathrm{~V}$ and from 0.72 to $0.76 \mathrm{~kg} / \mathrm{s}$, respectively. Total energy consumption during an assumed drying run of $72 \mathrm{~h}$ was $1587 \mathrm{Wh}$. Using a solar battery with an energy storage capacity of $912 \mathrm{Wh}$ and two PV modules with a total capacity of $200 \mathrm{~W}_{\mathrm{p}}$, the solar system was sufficient to power the fans without any interruption. As for comparison, measured data from air mass flow were added. A difference between the measured and the simulated air mass flow ranged between 0.03 and $0.10 \mathrm{~kg} / \mathrm{s}$. It could correspond to turbulent airflow at the outlet and any small leaks along the ISD. 

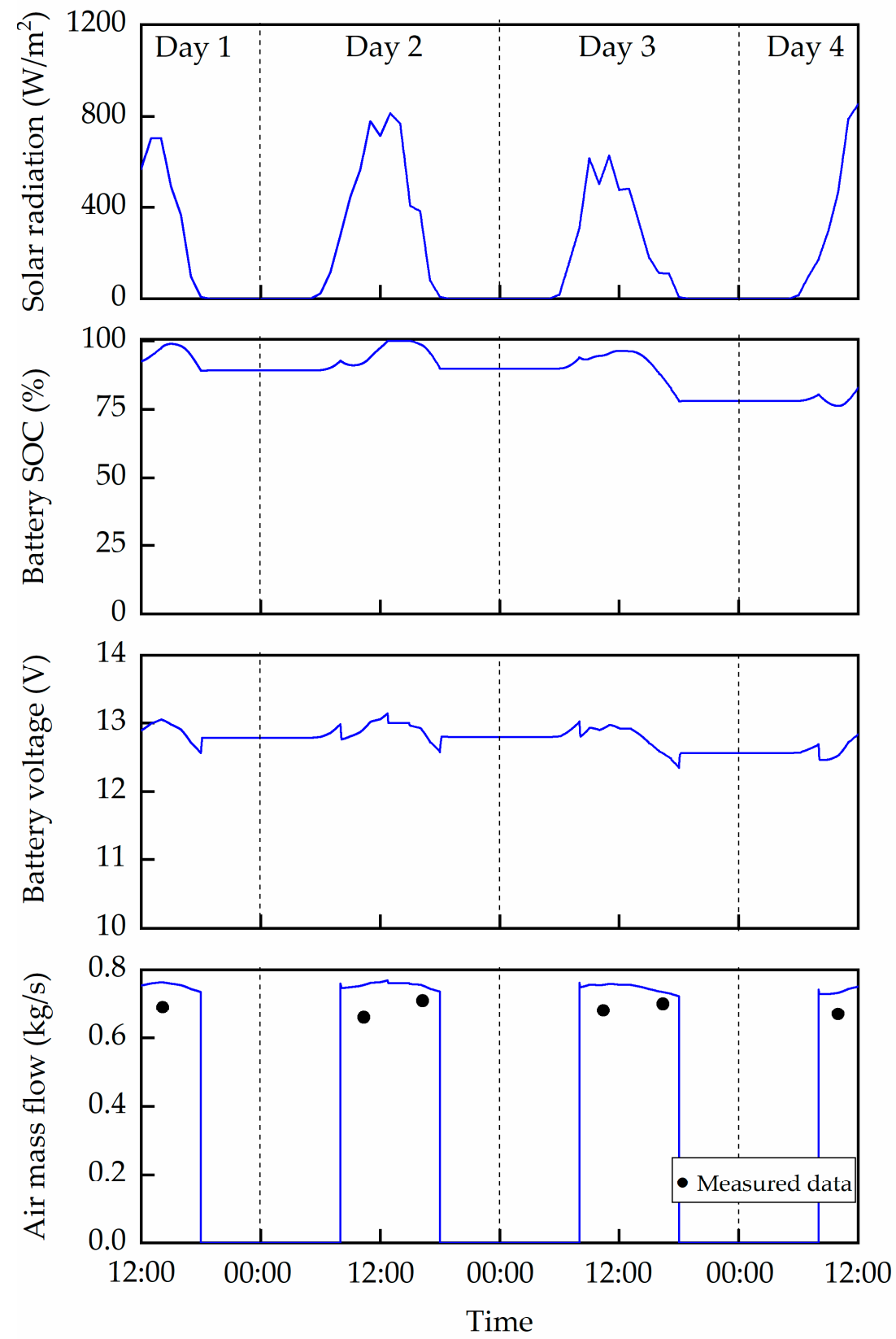

Figure 3. State-of-charge (SOC) and voltage of battery and air mass flow of an inflatable solar dryer (ISD) with two $100 \mathrm{~W}_{\mathrm{p}}$ PV modules and a $912 \mathrm{Wh}$ battery, estimated for solar radiation data of Nairobi, together with measured data for air mass flow (data points), Kenya, on 8-11 December 2016.

\subsection{Simulation of Airflow Distribution in the ISD}

Visualization of simulated airflow distribution and direction in the ISD (isometric and side view) and throughflow on the trays, i.e., exclusively vertical direction (top view), is presented in Figure 4. Air velocity inside the ISD varied between 0.5 and $1.5 \mathrm{~m} / \mathrm{s}$. High turbulence was visible in the preheating area. After the air deflector, air with high velocity passed across tray 1 to 5 . It could be seen that the stands allowed both through- and overflow of the air, particularly on those trays. The contact of the leaves with the air was intense, and the air velocity was high, with values between 0.5 and $0.7 \mathrm{~m} / \mathrm{s}$. This indicates that the leaves on those trays might have had a faster drying rate compared to the other trays. The following trays 6 to 20 showed mainly overflow at a relatively uniform air velocity of around $0.15 \mathrm{~m} / \mathrm{s}$. Close to the outlet, particularly tray 21 , turbulence was high again. 

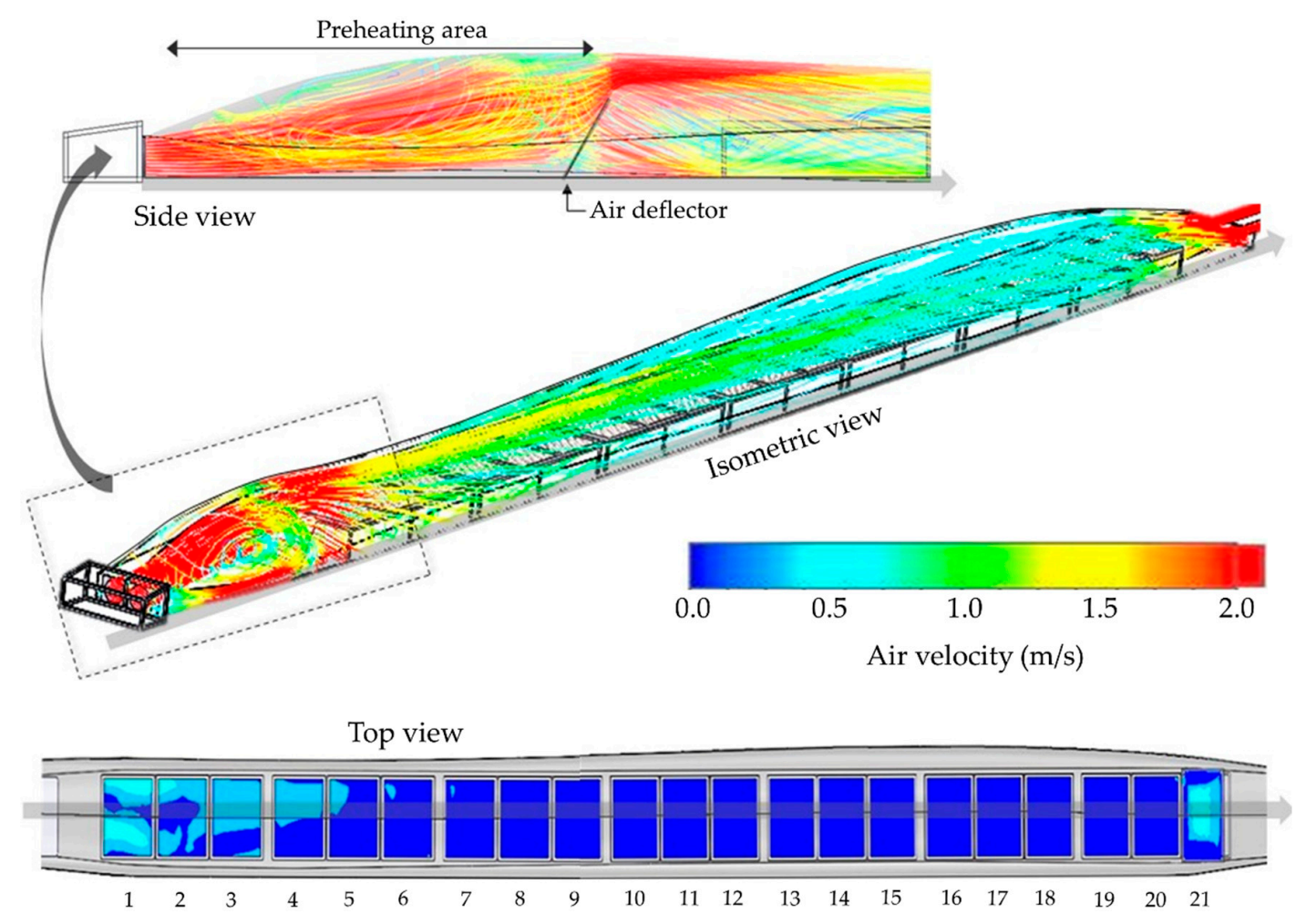

Figure 4. Visualization of airflow distribution and direction in the ISD (isometric and side view) and vertical flow through the 21 trays (top view).

Due to the spatial differences in intensity of the vertical component of the air flow and the increasing relative humidity of the dryer, the drying rate decreased along the dryer. Figure 5 presents the momentary moisture content of the amaranth leaves after $68 \mathrm{~h}$ of drying along the dryer. An increasing pattern of moisture content of the leaves as they got closer to the outlet was observed. The highest moisture content of leaves of 55.2\% was detected on tray 21.

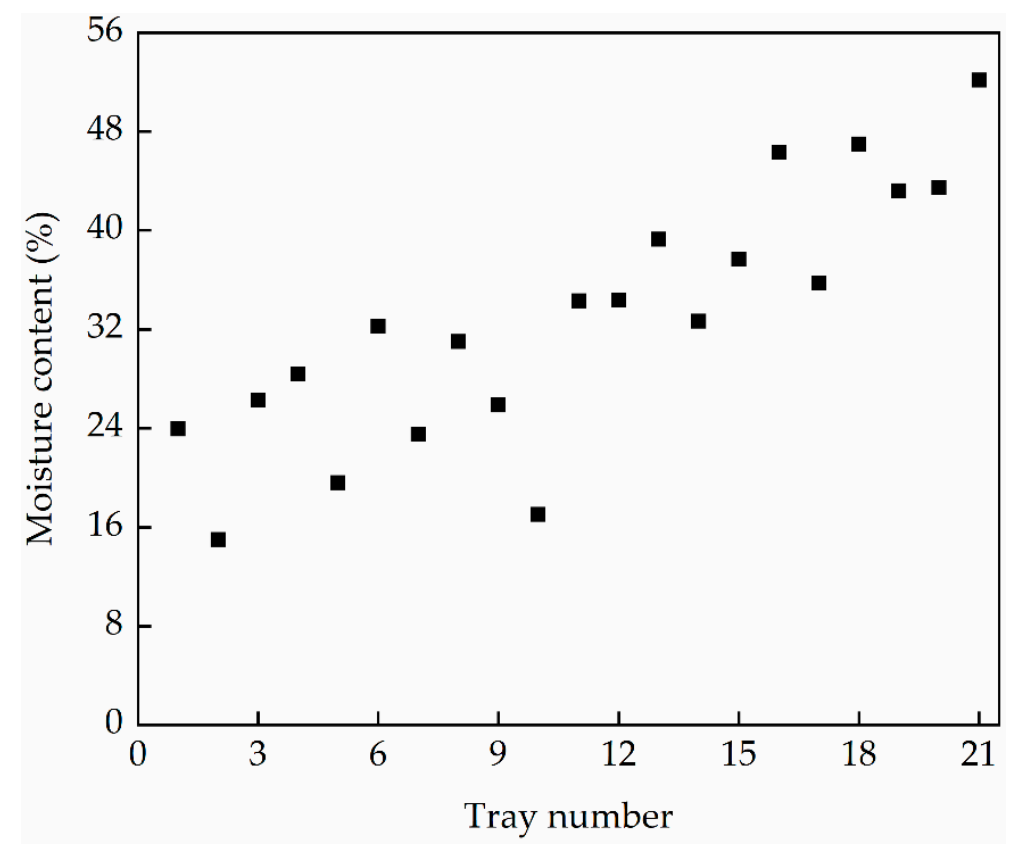

Figure 5. Momentary moisture content of leaves along the dryer (trays 1-21) in the ISD after $68 \mathrm{~h}$ of drying. 


\subsection{Drying Performance of the ISD Compared to Conventional Sun Drying}

Solar radiation and PV voltage, along with temperature and relative humidity inside the ISD, were compared to ambient conditions for a four-day drying experiment on 8-11 December 2016 and are shown in Figure 6. During the measurement period, bright cloud fields passed through and the sun was frequently shining through openings, causing frequent fluctuations in measured solar radiation and resulting in high peaks up to $1070 \mathrm{~W} / \mathrm{m}^{2}$. Same fluctuations were reflected in PV voltage, where values of 10.22 to $18.75 \mathrm{~V}$ were obtained for solar radiation of 510 to $950 \mathrm{~W} / \mathrm{m}^{2}$. Maximum PV voltage was $18.91 \mathrm{~V}$ and was achieved on December 8 (day 1) at 14:00. During the night, the ambient temperature and relative humidity could reach up to $18.0^{\circ} \mathrm{C}$ and $92.7 \%$. The highest recorded temperature inside the ISD was $63.4^{\circ} \mathrm{C}$ on December 9 at 14:09, while the ambient temperature was $45.4{ }^{\circ} \mathrm{C}$. Drying conditions at temperatures of $40^{\circ} \mathrm{C}$ or above were typically achieved in the ISD from 12:00 to 16:00. During the night, the ISD could show a lower temperature and a higher relative humidity than the ambient condition.
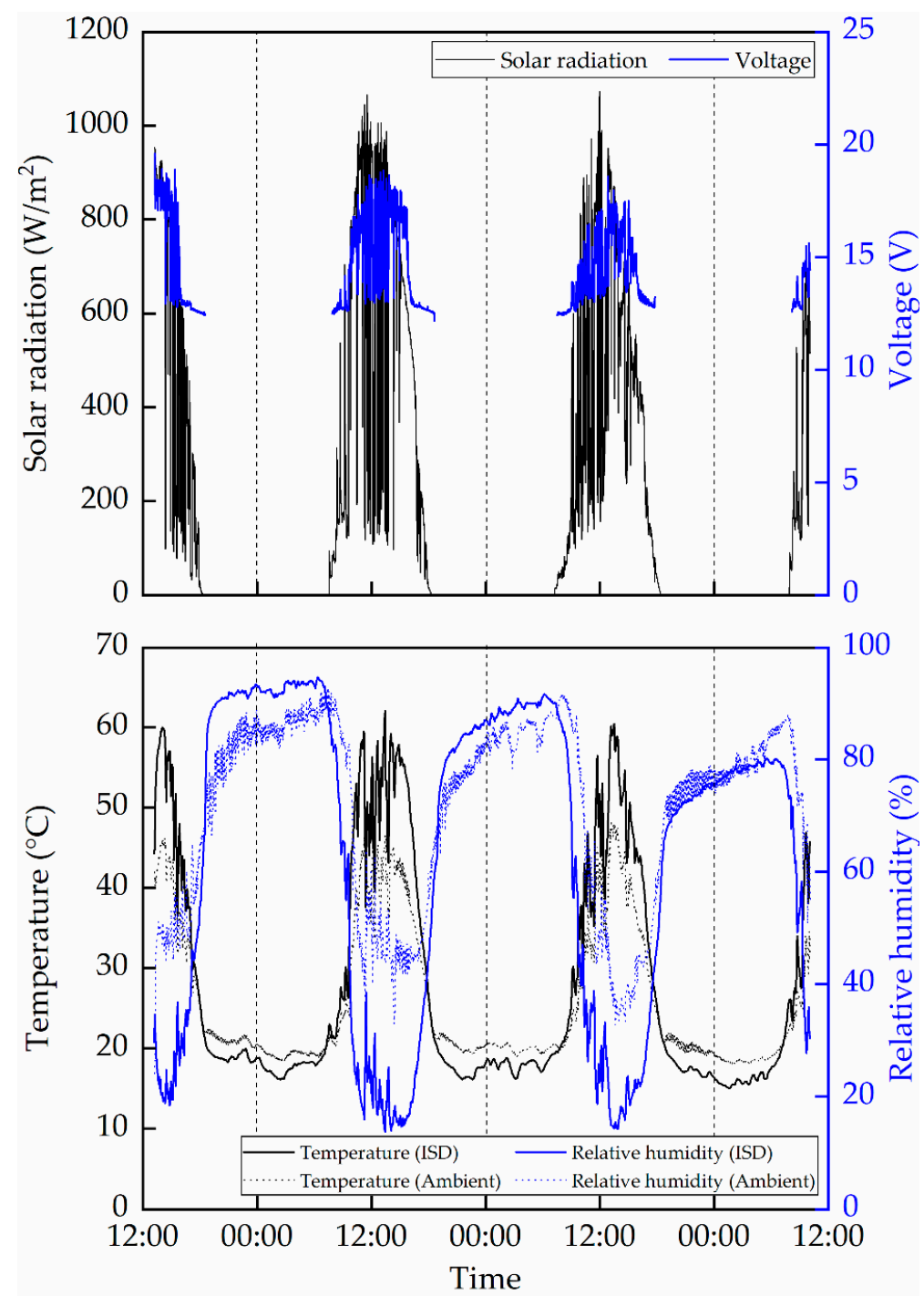

Figure 6. Solar radiation and voltage generated by the PV modules (top) and temperature and relative humidity in the ISD and ambient conditions (bottom) during the drying experiment on 8-11 December 2016.

Fluctuations of the temperature could be attributed to the opening of the zipper while mixing the leaves, which resulted in heat loss. In total, mixing the leaves on all 21 trays required around 3.5 to 
$4.5 \mathrm{~min}$. In order to minimize the opening time of the zipper, the mixing process should be done as efficiently as possible.

The drying curve of blanched amaranth leaves inside the ISD and under sun drying is presented in Figure 7. The total drying time was $68.08 \mathrm{~h}$, whereas the final moisture content of the leaves dried in the ISD and sun drying was $11.6 \%$ and $24.7 \%$ w.b., respectively. It can be seen that the ISD showed a better drying performance than sun drying, particularly on day 3 . In the night between days 3 and 4 , a visible reduction of the moisture content in the leaves under sun drying was detected. This might be due to lower relative humidity of the ambient air and occurrence of wind, which was observed during that night. A lower relative humidity of the air causes a higher vapor pressure deficit of the air, which accelerates the drying rate [26].

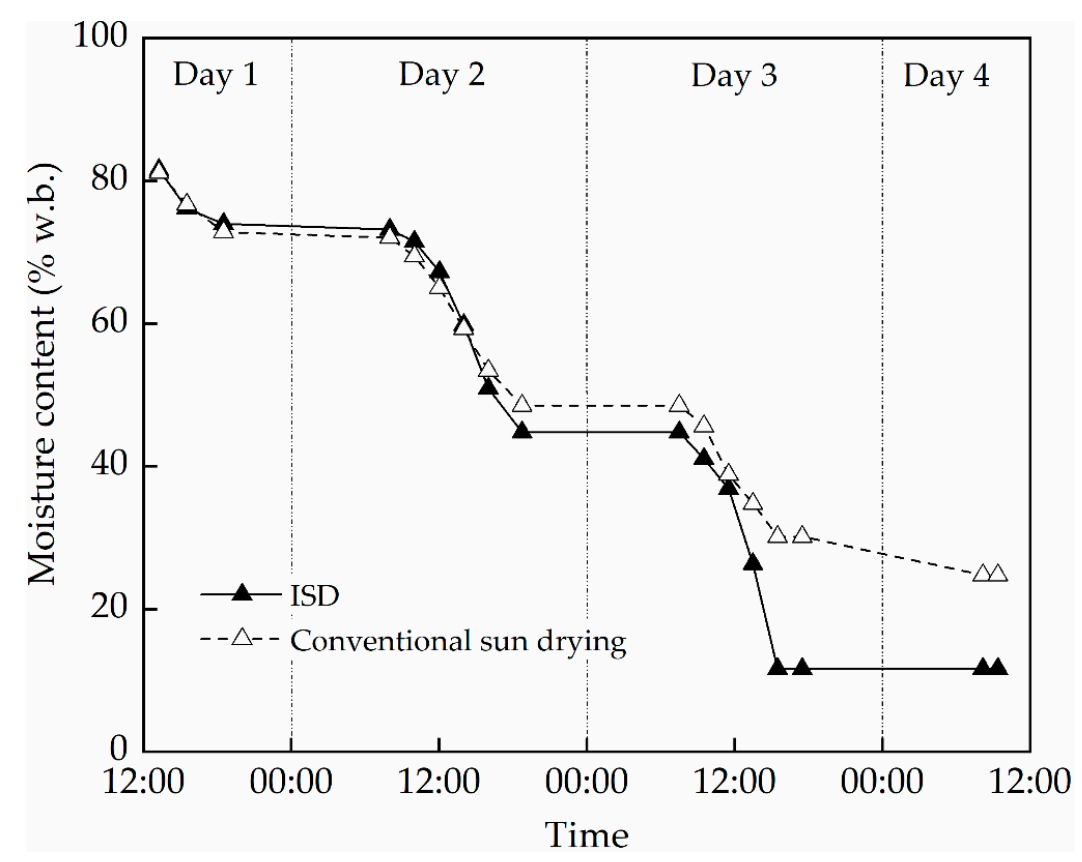

Figure 7. Moisture content (MC) over time of amaranth leaves dried in the ISD and under sun drying (8-11 December 2016).

A different pattern was reported in drying paddy rice using a previous type of the ISD, which resulted in a lower drying performance than sun drying during the dry season [13]. This might not be the case for amaranth leaves. Unlike paddy rice, amaranth leaves have no hulls or shells that form a resistance to moisture diffusion and thus reduce the drying rate [27].

By visual inspection, it was observed that the leaves were not dried uniformly. On the last day, leaves in the corners of the trays were not completely dried. This might have been caused by shading of the leaves by the black bottom layer, which was raised at both sides when the tunnel was inflated. To improve the design, the width of the black bottom layer in the ISD should be reduced.

Another aspect that lowered the drying performance of amaranth leaves was the presence of stalks. It was observed that the proportion of stalks in blanched leaves was around $41 \%$. At the end of drying, the stalks were less dry than the leaves, as shown in Figure 8. The stalks have an outer layer, which prevents water evaporation and therefore prolongs the overall drying time. In common practice, solar drying of leafy vegetables without the stalks takes only about $12 \mathrm{~h} \mathrm{[28].} \mathrm{The} \mathrm{optimum}$ time and method to dry the stalks should be further studied. The stalks are also a valuable commodity for amaranth leaf processors. In order to reduce the load in the dryer and accelerate the drying process, it is recommended to first unload the leaves soon after they are completely dried and then proceed with the stalks. 

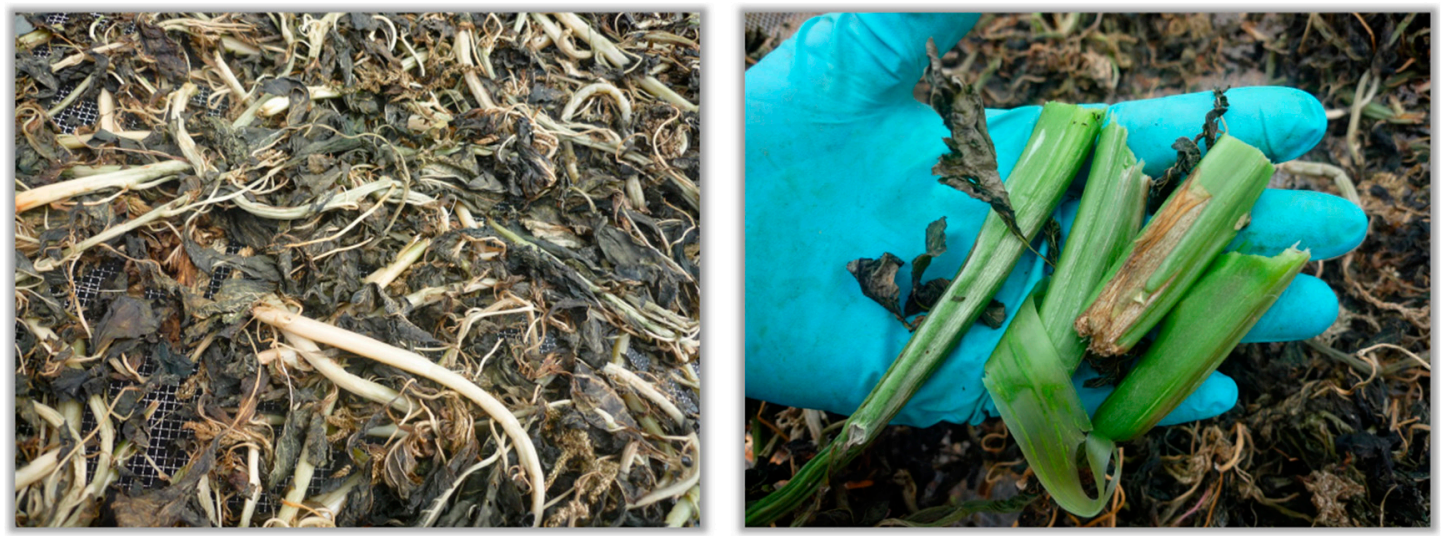

Figure 8. Amaranth leaves during drying with a high share of stalks (left) and the separated stalks (right).

\section{Conclusions}

The drying performance of an inflatable solar dryer for drying amaranth leaves was compared to conventional sun drying. The ISD showed potential as a mobile solar dryer for small and medium enterprises (SMEs) to accelerate the drying process of amaranth leaves and to protect the drying product from dust and insects. The temperature inside the ISD was considerably higher than the ambient temperature, and the drying rate of leaves was thus faster in the ISD than with sun drying. The air deflector integrated in the preheating zone showed the desired effect, i.e., to avoid blowing away dried leaves from the trays. As a further hardware improvement, it is recommended that the width of the black bottom layer of the ISD be reduced to avoid lateral shading of the drying product. To improve the drying process of amaranth leaves, the stalks should be separated from the leaves, chopped, and put on different trays for longer drying.

Further research should focus on a fan operation of the ISD also during the night for periods with favorable ambient conditions by increasing the battery capacity. Furthermore, advanced CFD modeling with an integration of mass and heat transfer should be used to further understand the influence of airflow distribution on the drying performance.

Author Contributions: Conceptualization, S.R., M.N., and J.M.; data curation, S.R.; formal analysis, S.R.; funding acquisition, C.G.K.C. and J.M.; investigation, S.R.; methodology, S.R.; project administration, M.N., S.S., C.G.K.C., and J.M.; resources, S.S., C.G.K.C., and J.M.; supervision, M.N. and J.M.; validation, S.R.; visualization, S.R.; writing—original draft preparation, S.R.; writing-review and editing, M.N., S.S., C.G.K.C., and J.M.

Funding: This research was financially supported by the German Federal Ministry for Economic Cooperation and Development (BMZ) through the project 15.7860.8-001.00 “Making Value Chains Work for Food and Nutrition Security of Vulnerable Populations in East Africa", led by the International Center for Tropical Agriculture (CIAT).

Acknowledgments: The authors are grateful to Mercy Lung'aho, Anthony Ngoto, and Juliet Ogola from the International Center for Tropical Agriculture (CIAT) for all the facilities and support. The authors also express gratitude to Jackson Otenga as operational manager and Tei Mukunya as CEO of Azuri Health in Kenya for their support during field experiments. The authors would also like to thank Sabine Nugent for language editing.

Conflicts of Interest: The authors declare no conflict of interest.

\section{References}

1. Grabowski, S.; Ramaswamy, H.S.; Marcotte, M. Drying of fruits, vegetables, and spices. In Handbook of Postharvest Technology: Cereals, Fruits, Vegetables, Tea, and Spices; Ramaswamy, H.S., Raghavan, G.S.V., Chakraverty, A., Mujumdar, A.S., Eds.; Marcel Dekker Inc.: New York, NY, USA, 2003; pp. 653-695.

2. Janjai, S.; Bala, B.K. Solar Drying Technology. Food Eng. Rev. 2012, 4, 16-54. [CrossRef]

3. Müller, J.; Mühlbauer, W. Solar drying. In Modern Drying Technology; Tsotsas, E., Mujumdar, A.S., Eds.; Wiley-VCH Verlag GmbH \& Co. KGaA: Weinheim, Germany, 2011; pp. 199-243. 
4. Jebur, H.A.; Jabr, A.K.; Jassim, S.Y. Evaluation of thermal efficiency for solar energy storage of agricultural products: A review. Plant Arch. 2019, 19, 17-24.

5. Sharma, V.K.; Colangelo, A.; Spagna, G. Experimental investigation of different solar dryers suitable for fruit and vegetable drying. Renew. Energy 1995, 6, 413-424. [CrossRef]

6. Amir, E.J.; Grandegger, K.; Esper, A.; Sumarsono, M.; Djaya, C.; Mühlbauer, W. Development of a multi-purpose solar tunnel dryer for use in humid tropics. Renew. Energy 1991, 1, 167-176. [CrossRef]

7. Singh, P.; Shrivastava, V.; Kumar, A. Recent developments in greenhouse solar drying: A review. Renew. Sustain. Energy Rev. 2018, 82, 3250-3262. [CrossRef]

8. Khazimov, M.Z.; Khazimov, K.M.; Urmashev, B.A.; Tazhibayev, T.S.; Sagyndykova, Z.B. Intensification of the Plant Products Drying Process by Improving Solar Dryer Design. J. Eng. Thermophys. 2018, 27, 580-592. [CrossRef]

9. Sai Krishna Teja, M.; Narasimha Rao, K.V.; Pochont, N.R. Design, development and experimental evaluation of solar dryer. Int. J. Mech. Prod. Eng. Res. Dev. 2018, 8, 949-968.

10. Noh, A.M.; Mat, S.; Ruslan, M.H. CFD simulation of temperature and air flow distribution inside industrial scale solar dryer. J. Adv. Res. Fluid Mech. Therm. Sci. 2018, 45, 156-164.

11. Orbegoso, E.M.; Saavedra, R.; Marcelo, D.; La Madrid, R. Numerical characterisation of one-step and three-step solar air heating collectors used for cocoa bean solar drying. J. Environ. Manag. 2017, 203, 1080-1094. [CrossRef]

12. Lutz, K.; Mühlbauer, W. Solar tunnel dryer with integrated collector. Dry. Technol. 1986, 4, 583-603. [CrossRef]

13. Salvatierra-Rojas, A.; Nagle, M.; Gummert, M.; de Bruin, T.; Müller, J. Development of an inflatable solar dryer for improved postharvest handling of paddy rice in humid climates. Int. J. Agric. Biol. Eng. 2017, 10, 269-282.

14. Ng'Ang'A, M.N.; Muasya, R.M.; Omami, E.; Ohiokpehai, O. Effect of environment, intercropping systems and harvest intervals on protein and $\beta$-carotene contents of leaf Amaranth. Acta Hortic. 2011, 911, 433-436.

15. Liu, F.; Stützel, H. Leaf water relations of vegetable amaranth (Amaranthus spp.) in response to soil drying. Eur. J. Agron. 2002, 16, 137-150. [CrossRef]

16. Nzomo, E.M.; Ariyawardana, A.; Sila, D.N.; Sellahewa, J.N. Reaping the potential benefits of amaranth: Value chain challenges ahead for Kenya. In Acta Horticulturae; Mecozzi, M., Srinivasan, R., Keatinge, J.D.H., Eds.; International Society for Horticultural Science: Leuven, Belgium, 2015; Volume 1102, pp. 191-198.

17. Oliveira, S.M.; Brandão, T.R.S.; Silva, C.L.M. Influence of Drying Processes and Pretreatments on Nutritional and Bioactive Characteristics of Dried Vegetables: A Review. Food Eng. Rev. 2016, 8, 134-163. [CrossRef]

18. Negi, P.S.; Roy, S.K. Effect of Blanching and Drying Methods on $\beta$-Carotene, Ascorbic acid and Chlorophyll Retention of Leafy Vegetables. LWT Food Sci. Technol. 2000, 33, 295-298. [CrossRef]

19. Oboh, G. Effect of blanching on the antioxidant properties of some tropical green leafy vegetables. LWT Food Sci. Technol. 2005, 38, 513-517. [CrossRef]

20. Sukamongkol, Y.; Chungpaibulpatana, S.; Ongsakul, W. A simulation model for predicting the performance of a solar photovoltaic system with alternating current loads. Renew. Energy 2002, 27, 237-258. [CrossRef]

21. Torres-Toledo, V.; Meissner, K.; Täschner, P.; Martınez-Ballester, S.; Müller, J. Design and performance of a small-scale solar ice-maker based on a DC-freezer and an adaptive control unit. Sol. Energy 2016, 139, 433-443. [CrossRef]

22. Poblete, R.; Cortes, E.; Macchiavello, J.; Bakit, J. Factors influencing solar drying performance of the red algae Gracilaria chilensis. Renew. Energy 2018, 126, 978-986. [CrossRef]

23. Dassault Systèmes. Technical Reference-Solidworks Flow Simulation 2017; Dassault Systèmes: Vélizy-Villacoublay, France, 2017.

24. Zogzas, N.P.; Maroulis, Z.B.; Marinos-Kouris, D. Densities, shrinkage and porosity of some vegetables during air drying. Dry. Technol. 1994, 12, 1653-1666. [CrossRef]

25. DIN CEN/TS 14774-3. Determination of moisture content-oven dry method. In Part 3: Moisture in General Analysis Sample; Deutsches Institut für Normung e.V.: Berlin, Germany, 2004.

26. Pereira, L.S.; Allen, R.G.; Smith, M.; Raes, D. Crop evapotranspiration estimation with FAO56: Past and future. Agric. Water Manag. 2015, 147, 4-20. [CrossRef] 
27. Sharma, A.; Chen, C.R.; Vu Lan, N. Solar-energy drying systems: A review. Renew. Sustain. Energy Rev. 2009, 13, 1185-1210. [CrossRef]

28. Sobukola, O.P.; Dairo, O.U.; Sanni, L.O.; Odunewu, A.V.; Fafiolu, B.O. Thin layer drying process of some leafy vegetables under open sun. Food Sci. Technol. Int. 2007, 13, 35-40. [CrossRef]

(C) 2019 by the authors. Licensee MDPI, Basel, Switzerland. This article is an open access article distributed under the terms and conditions of the Creative Commons Attribution (CC BY) license (http://creativecommons.org/licenses/by/4.0/). 